\title{
Tuvalu Visualization Project - Net Art on Digital Globe: Telling the Realities of Remote Places
}

\author{
Makiko Suzuki Harada, Hidenori Watanave ${ }^{1}$ and Shuuichi Endou ${ }^{2}$ \\ ${ }^{1}$ Faculty of System Design, Tokyo Metropolitan University \\ ${ }^{2}$ NPO Tuvalu Overview Industrial Art Course; Faculty of System Design, Tokyo \\ Japan
}

\section{Introduction}

\subsection{About this study}

Tuvalu Visualization Project is a net-art-work on digital globe that tells the realities of remote places. Existent Internet archive contents were able to have only the collection of landscape photos, but were not able to show reality of the people and life. And also not able to develop communication between users and remote places based on archives.Then this study propose the method of at the point of design using the digital globe. Our art work based on the proposal technique was able to be experienced by many users at real exhibitions, especially through the internet, the Web site access is 13270 times. At real exhibition, the work enabled users to inspect of the situation of the local area threedimensionally, as well as the creation of solidarity through the visualization of pseudosynchronous communication. This archive work was developed by only open sourse software and anyone can download and distribute free-of-charge from the internet. Furthermore, the authors attempt to use the result of this study in helping support the international philanthropic activities by individual and non-profit organization.

As stated above, this chapter state the Background and purpose, the chapter 2 will state the Related Studies, the chapter 3 will state the composition of this art work in detail.

The chapter 4 will state the cosideration and the chapter5 will state the Conclusion and Outlook.

\subsection{Background and purpose of this study}

Through the popularization of search engines and social network services, it has become possible to easily obtain via internet the information relating to remote places, not available before. However, because the information search solely takes place based on keywords and meta tags, the more sensational and one-sided information-such as major accidents and disasters-tend to be communicated firstly, and more multifaceted and unaffected truth is not easily communicated. Such tendency is especially strong in developing countries and remote islands, due to the low saturation level of the internet use, making it difficult to webcast individually. This situation prevents the understanding between cultures and people living in remote places, with the presence of the language barrier adding to the problem. Therefore, the phenomenon happening in distant and far places is likely to be taken as things of no concern, and is difficult to be considered in relation to one's daily life. 
This study has the purpose of analyzing different devices appropriate to create an opportunity to reconsider globally the phenomenon in far and distant places in relations to people's daily lives. Furthermore, the authors attempt to use the result of this study in helping support the international philanthropic activities by individual and non-profit organizations. As a starter, the authors have visualized on the digital globe the "realities" of the remote place, which is many-sided in its state. Furthermore, we have developed an internet content which includes the pseudo-synchronous communication function relating to it. The "Tuvalu Visualization Project" (Fig.1) presented in this thesis is an net art work with both the functions of a photographic archive of the people and their daily life scenes of the remote islands in the South Pacific, the Tuvalu Islands, broadcasted via the digital globe on the internet, as well as a communication platform.

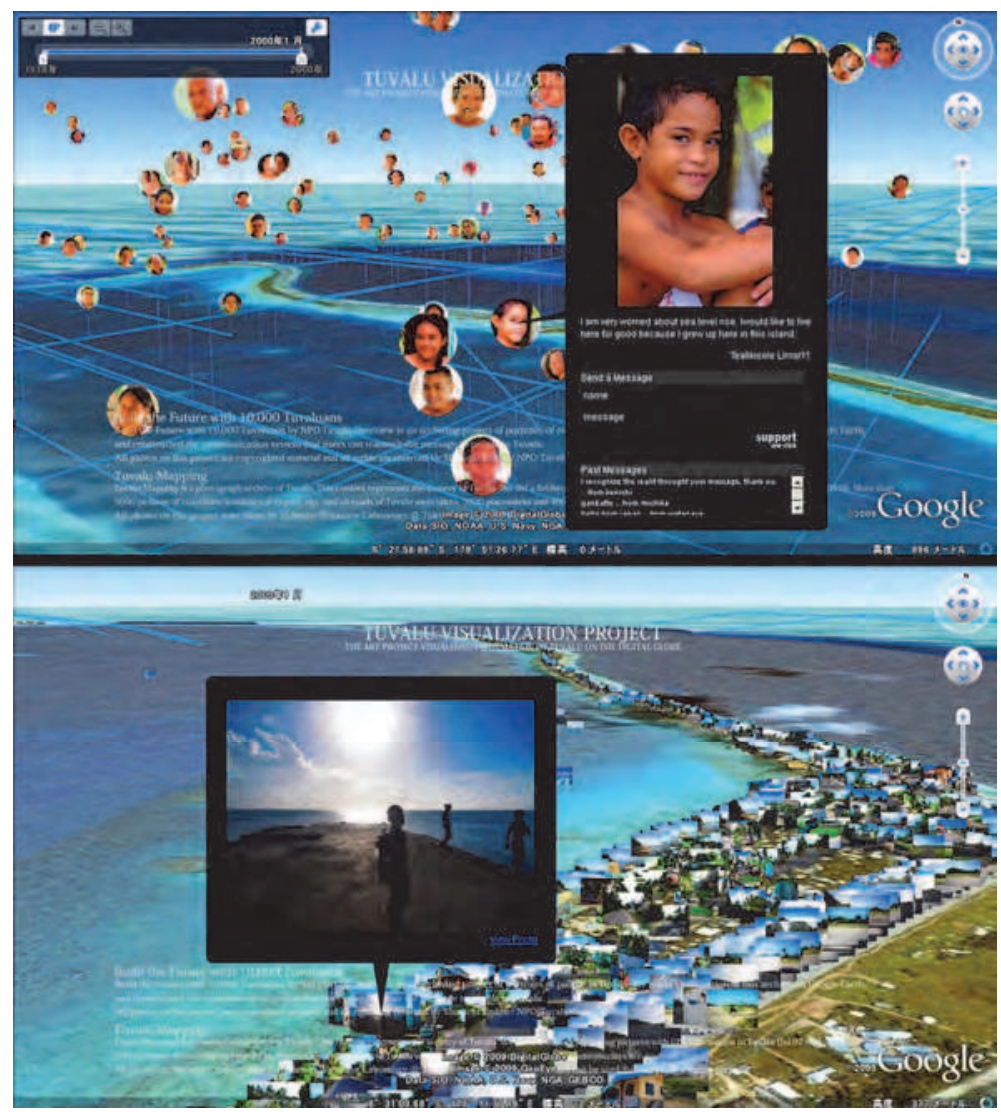

Fig. 1. Tuvalu visualization project

\subsection{The definition of "Reality" in this study}

The word "Reality" has the meaning of "the real state of affairs". The origin of the word comes from the Buddhist term "tattrasyalakSaNam", referring to the truth unable to be measured by the heart, and separating from the human's superficial words. In the case of 
sociology, this word is used to mean the general image which emerged from the collection of abundant data concerning the phenomenon, as in "The Collaborate Study: the Realities of the Damages due to the Atomic Bomb in Hiroshima-Nagasaki", in which researchers in various fields analyzed the complicated aspects of the atomic bombing. Furthermore, in the case of field of arts, especially in regards to the activity of photographers, the word has been used to mean the "real state of affairs" of events and accidents, expressed through photographs of people and scenes, not communicated by the mass media. Based on this, this study defines the word "reality" as the state of the townspeople living locally as well as their daily life scenes, which is not able to be communicated through the one-sided report relating to remote places. Also, the art work used as two of its components the "Record of Portraits and Interviews" as well as "Landscape Photographs" collected in the Tuvalu Islands. The choice of the subject matter and material will be mentioned in more details in 3.2.

\section{Related studies}

Needless to say, the internet fraught with problems mentioned in 1.1, is also a favorable place for those who expresses and sends information individually. The "Net Art" with the internet being the medium, accessible by people all over the world, has been utilized as a means to send the author's message throughout the world. In recent years, there are cases, such as the "Niko Niko (Smile) Animation", where the connection itself is expressed which was formed between the people through the art work, intended to be a communication platform. Such works are beginning to replace the existent media, i.e. the television. Out of the preceding art works, this study has especially referred to those that connect stories and places complementarily, and which has the intension of reinforcing each area as well. The digital map rapidly spreading in recent years, has been considered suitable for the purpose of "knowing and extracting the connection between our real location and the world". This is in accordance with the purpose of this study mentioned in 1.1. As examples of preceding cases of net art works utilizing the digital map, there exist the "Sensorium" which re-expresses the various data existent in the world by visualizing it upon the digital map; the "CCTV" which is a part of the global panopticon where the user watches a local area using surveillance cameras; and the "Field-Works" which made it possible to relive the past memories of another by the placement of photographs and images in the virtual space based on GPS information. These are net art works broadcasted one-way via the internet. However, in recent years, works of two-way communication have been released, in which the general user contribute data, such as the "Life Slice Camera", the "Jikukan-Poemer+Kakiko map", and the "Sakura Mapping". The "Sakura Mapping" especially is an excellent example of individually oriented daily life communicated publicly on the digital globe. The general user visualized photographs of cherry blossoms taken by mobile phone cameras with GPS function by mapping them on to the digital globe, the "Google Earth". Moreover, there also exist the feature of being able to be viewed easily by anyone using a personal computer at home, where it is broadcasted via the already widespread internet service. However, these works have only the collection of landscape photos as its theme, and is not able to show the state of the people. Therefore, it is insufficient to "tell the realities of the remote places", as is the purpose of this study. Also, it has become more difficult today to transmit images of people, due to the increased feeling of resistance to publicly exhibiting images of people on the internet, in view of the protection of personal information. This problem can be solved by developing the social activity of obtaining the permission to publicly broadcast via the internet. Through diligently explaining 
the purpose in producing the work, the understanding of people, who are the objects of photography, may be gained. There exist an effort to communicate the images of the people living in remote places, at the same time joining the social movement, which is called the "Crisis in Darfur", with the theme of the Darfur Crisis. In this piece of work, it is possible to view the state of remote places in detail on the digital globe, as well as to inspect the images of the people who live there and their experiences. Even though "the stories and the places tie closely together, and the reality of the tragedy happening in the remote place is communicated, with the possibility of increasingly evoking the viewer's action", there still remains the misgiving of it "taken as things of no concern" as mentioned beforehand. On the other hand, in the precedented case of the net art work with the intention to be a communication platform, in relation to the uploaded contents, the "Niko Niko (Smile) Animation", through adding the communication function of pseudo-synchronously replaying the comments of the user, the sense of solidarity between the users is created. It is also successful in producing the sense of the everyday life, as if talking over a coffee table. This point is the focus of this study, and the authors have chosen to create a new net art work combining both the contents on the digital globe, showing the realities of remote places through covering the images of people and the scenes of their daily life thoroughly, as well as the pseudo-synchronous communication function related to it. The next chapter will state the composition of this art work in detail.

\section{Composition of the art work}

\subsection{Purpose of the art work}

The authors, with the above discussion in mind, have decided to create a net art work, combining the contents on the digital globe that covers the images of the people and the scenes of their daily life extensively - telling the realities of remote places - and the pseudosynchronous communication function related to it. Through this art work, by communicating not only sensational and one-sided information, but also providing manysided realities of the remote place, it is possible to create a sense of solidarity using the pseudo-synchronous communication. It is also possible to create an opportunity to recognize anew the local problems globally, by viewers overlapping the phenomenonthought of as things of no concern up til now-in their own lives.

\subsection{Choice of theme and collection of source materials}

From the olden times, photographs were used as a means to bring out the realities of the object taken. Many photographic art work exist which has high artistic value, stepping into the interior of a person. Also, in comparison to the yet unified sound/video format, the imaging format, i.e. jpeg, is possible to be displayed on almost all platforms, and the size of the data is relatively small. For these reasons, photographs are used as the subject matter in this art work. Moreover, as stated in chapter 2, in the course of publicly exhibiting images of people via the internet, it is essential to have solidarity with the social activities developed at the local level. With this point in mind, Tuvalu was taken up as the theme of this art work. It will be stated in detail hereafter.

Tuvalu is an island nation in the South Pacific, known for having the danger of its land going under water, due to the rise of the sea level originating from global warming. It is also known as the country for which domain name, .tv, was allotted. While articles tying together Tuvalu and submerging of its land, or relating to the .tv domain, rank high in the search engine, it is 
difficult to know the real state of the people living in Tuvalu and scenes of their daily life on the other hand. Moreover, because the internet access in Tuvalu is dependent on the communication circuit of the artificial satellite, with it being narrow band and unstable (as of July, 2009), it is difficult to webcast individually. The Non-Profit Organization Tuvalu Overview(TOV) has started a social action program since 1998 with a project called, "Build the Future with 10000 Tuvaluans". It is part of the movement to communicate the lifestyle and culture of Tuvalu and the people living there, as well as the damage they face. TOV undertook to interview all 10,000 Tuvaluan citizens throughout the nine islands within the Tuvalu nation in order to draw out the realities of the people of Tuvalu. The real voices, such as their values, dreams, and wishes for the developed countries, are archived as interview records, and at the same time the portrait of each citizen is photographed. This project has proceeded mainly as photo exhibitions at actual places. However, the webcasting on the internet has been limited to the conventional Web site. From these conditions, Tuvalu was chosen as the theme of the net art work, and the portraits and interview records of 400 citizens of the Island of Nukulaelae, in the Southern part of Tuvalu - fruit of the "Build the Future with 10000 Tuvaluans" projectwere utilized in creating the art work.

In the "Build the Future with 10000 Tuvaluans" project, the photographs of scenes of daily life are not covered enough, and it is one of several elements in communicating the realities of a remote place. In order to collect the landscape photographs of Tuvalu, the authors did a fieldwork from July 5th through the 24th in the year 2009. In communicating the reality of Tuvalu, it is desirable to gather photographs based on the point of view of the local people, not affected by the preconceptions of Tuvalu held by a foreigner as the photographer. Thereupon, in the attempt to minimize the inclusion of the will of the photographer, it was worked out that the photographs were taken every 10 (seconds) at a set angle, without looking through the finder. In the event of taking the photographs, the GPS unit, "GPS-CS3K" and a digital camera were used together, and 5017 images with GPS information were taken. After excluding those blurred or with low light intensity, 3602 images were mapped out. In addition to that, high resolution landscape photographs taken in various places in Tuvalu - through the "Build the Future with 10000 Tuvaluans" project - were also used.

\subsection{Selecting the platform}

The digital globe, "Google Earth", can be downloaded free-of-charge from the internet, and it is a 3-Dimensional digital globe software, able to be used on Windows/Mac/Linux. The end-user can zoom in on the preferred place on Earth, and view the detailed satellite images mapped out on the three-dimensional land form. Also, the viewer is able to grasp in global scale the distance and the position of the place in relation to the place of one's living. Furthermore, a variety of expression is possible through $\mathrm{kml}$ (KeyholeMarkupLanguage) in "Google Earth", where one can document the contents by using functions such as the place mark, overlay, polygon, and time slider. Also, by applying the JavascriptAPI, an excellent feature is seen where the communication over the internet of contents including the geographic and time information is made simple. These merits satisfy one of the purpose stated in chapter 3.1, which is to "communicate the many-sided realities of remote place by connecting it to a place on Earth". Added to this, it has been downloaded a total of over one hundred million times, and it is speculated that many numbers of users are employing this software. This point satisfies the purpose of "creating the solidarity through pseudosynchronous communication". With these points in mind, the "GoogleEarth" was chosen as the platform. Still, the state of Tuvalu was made easy to grasp, for the entire region of 
Tuvalu was the object of high resolution satellite images (aerial photographs) mapped out on "GoogleEarth" (as of July, 2009).

\subsection{Portraits and interview records}

The portraits and interview records from the "Build the Future with 10000 Tuvaluans" are placed as a content, designed as a net art where the viewers are able to browse all the portraits related to a place, or equivalently in a 3D space, taking advantage of the feature of "Google Earth" in which contents are able to be placed in 3-D space.

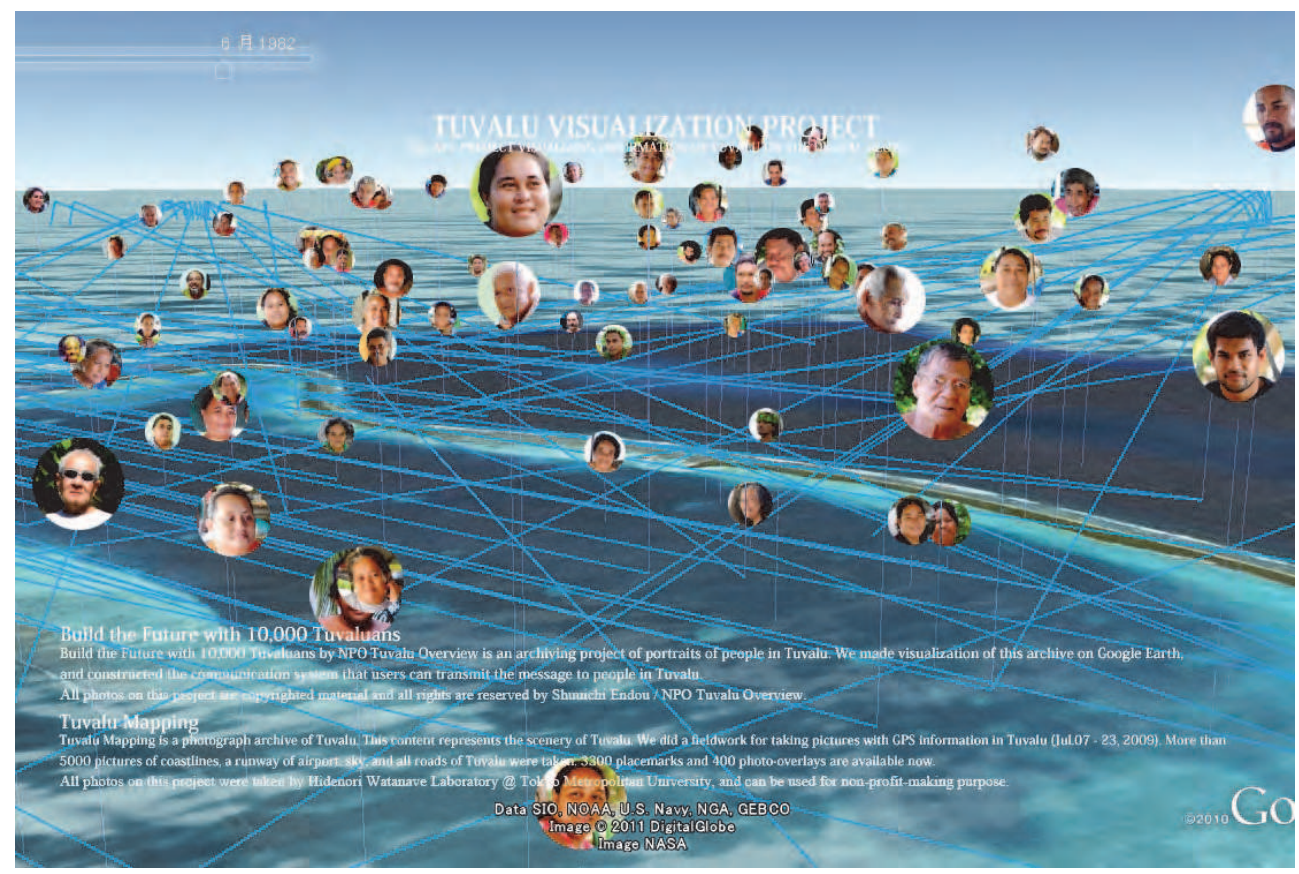

Fig. 2. Portraits mapping

As in the precedented cases stated in chapter 2, if the group of portraits are mapped out based on the point of photography, there exists the merit of being able to grasp the information of the people connected to a place. However, many icons will be crowded within a small area, and the visibility will be lacking. Also, by the habit of each viewer, it is expected to produce a difference in the opportunity for inspection of each portrait. Therefore, it has been designed to switch between two modes of display, one based on the positional information, and the other randomly positioned. In the case of the random positioning, the group of portraits are displayed randomly as icons in the air above the whole region of Nukulaelae Island, the place of photography (Fig. 2). In addition to the latitude and longitude, the altitude is also made random, and the user is able to tilt the camera in order to see the photographs equivalently. The zoom-in/out and pan function can be used to freely fly between the icons, enabling the user to find the preferred person. The two modes of display can be switched around by the viewer rereading the $\mathrm{kml}$ at an arbitrary timing. All icons has the timespan tag according to the age of the citizen 
photographed, and it is possible to narrow down the display based on the age using the Google Earth time slide (Fig.3).

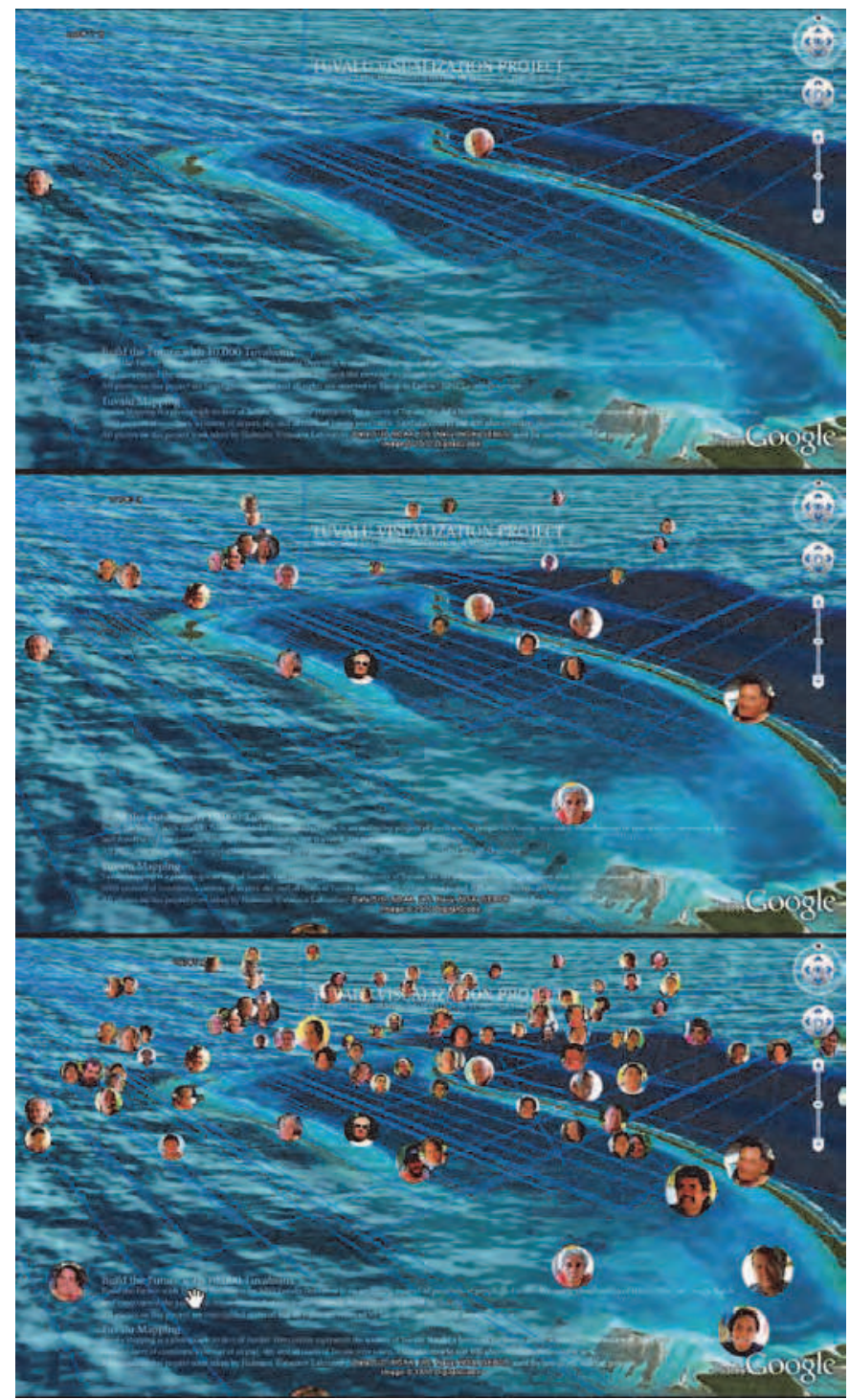

Fig. 3. Narrowing display by timespan

Clicking on the icon will display a balloon (Fig.4). Within the balloon, a large-sized photograph (Maximum width of 320 (pixel)), name, age, and a comment entry form are displayed. 


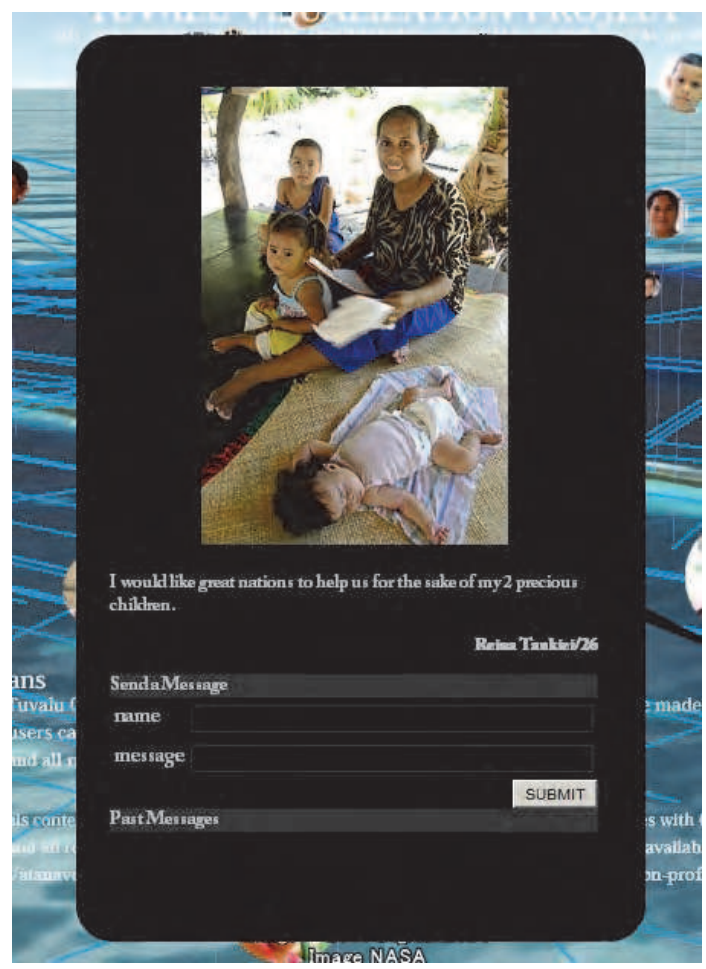

Fig. 4. Balloon display

The mapping of landscape photographs, the other contents enabling the visualization of the "realities of the daily life", will be stated later.

\subsection{Sending the comment and visualization of the communication}

In order to realize the "pseudo-synchronous communication function" mentioned in 3.1, a system has been implemented to visualize pseudo-synchronously the communication exchanged between the Tuvaluans and the users through lines on the digital globe. After the user enters the name and comment into the comment entry form in the balloon explained in 3.4, a line is drawn between the location of the user on the Earth and the portrait icon of the person whom the comment was sent to. The location of the user is estimated by the IP geolocation method. As the comment is sent, the global IP address of the user is verified with the MaxMind GeoIP database (MaxMind) of the server simultaneously, estimating the location information. A line is drawn on the Google Earth through the following system. When the network link $\mathrm{kml}$ of the client side accesses the PHP for line output of the server side, the $\mathrm{kml}$ file, including each location information of both the user and the portrait icon, is downloaded. All the comments contributed so far will be displayed within the balloon. Through this system, the record of the communication is expressed as the group of lines drawn from various places on Earth. 
This allows the pseudo-synchronous visualization of the expanse of global communication including Tuvalu (Fig.5).

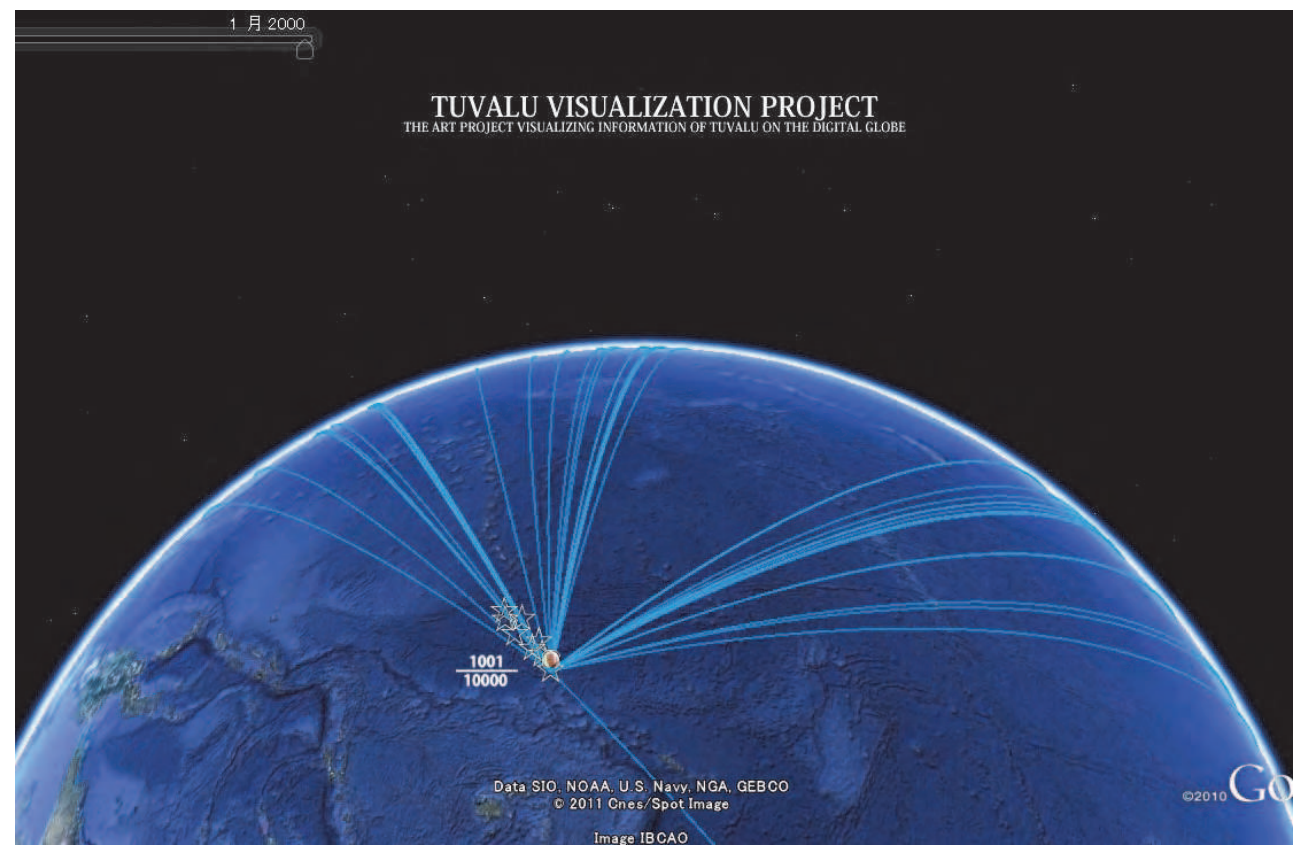

Fig. 5. Displaying lines

\subsection{Mapping of the landscape photographs}

As another content to tell the realities of a remote place, mapping of photographs with GPS information, as well as super high resolution photo overlay were created. All photographs were mapped out at the points of shooting, and displayed as icons on the Google Earth. Because the visibility is decreased when the icons are mapped out on the ground surface, sinking into the satellite images, all the icons are set at an altitude of $+15[\mathrm{~m}]$ above ground surface. Through this design, the photographs and the ground surface are displayed separately by tilting the camera. It is possible to search the landscape photograph of liking, while flying around freely between the icons by using the zoom-in/out and panning functions (Fig. 6)

Moreover, twenty landscape photographs taken all over Tuvalu have been implemented as super high resolution photo overlay. Each photo is divided into 256 pieces to be uploaded into the server. They are displayed in multi-layers on the 3D land form in the Google Earth using the photooverlay tag (Fig.7). Also, images with resolution dependent on the degree of zooming-in are automatically displayed in the streaming format. 


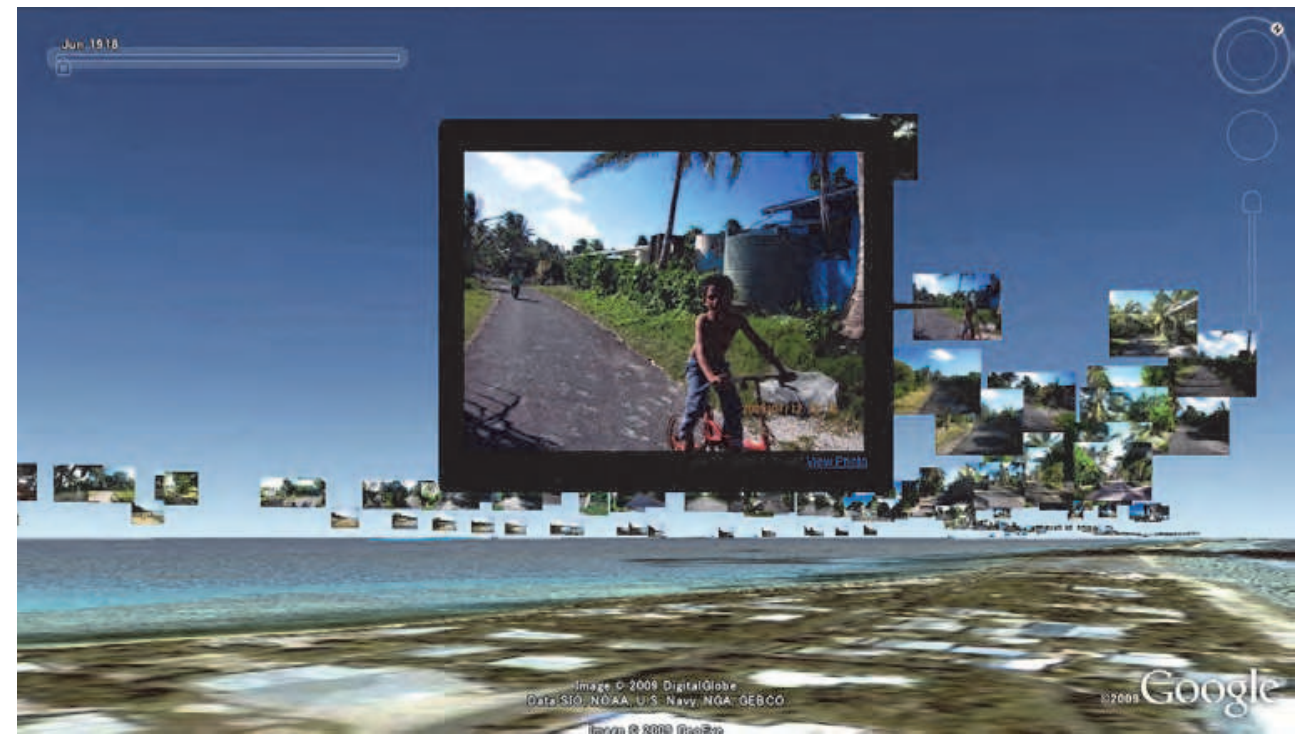

Fig. 6. GPS photograph mapping

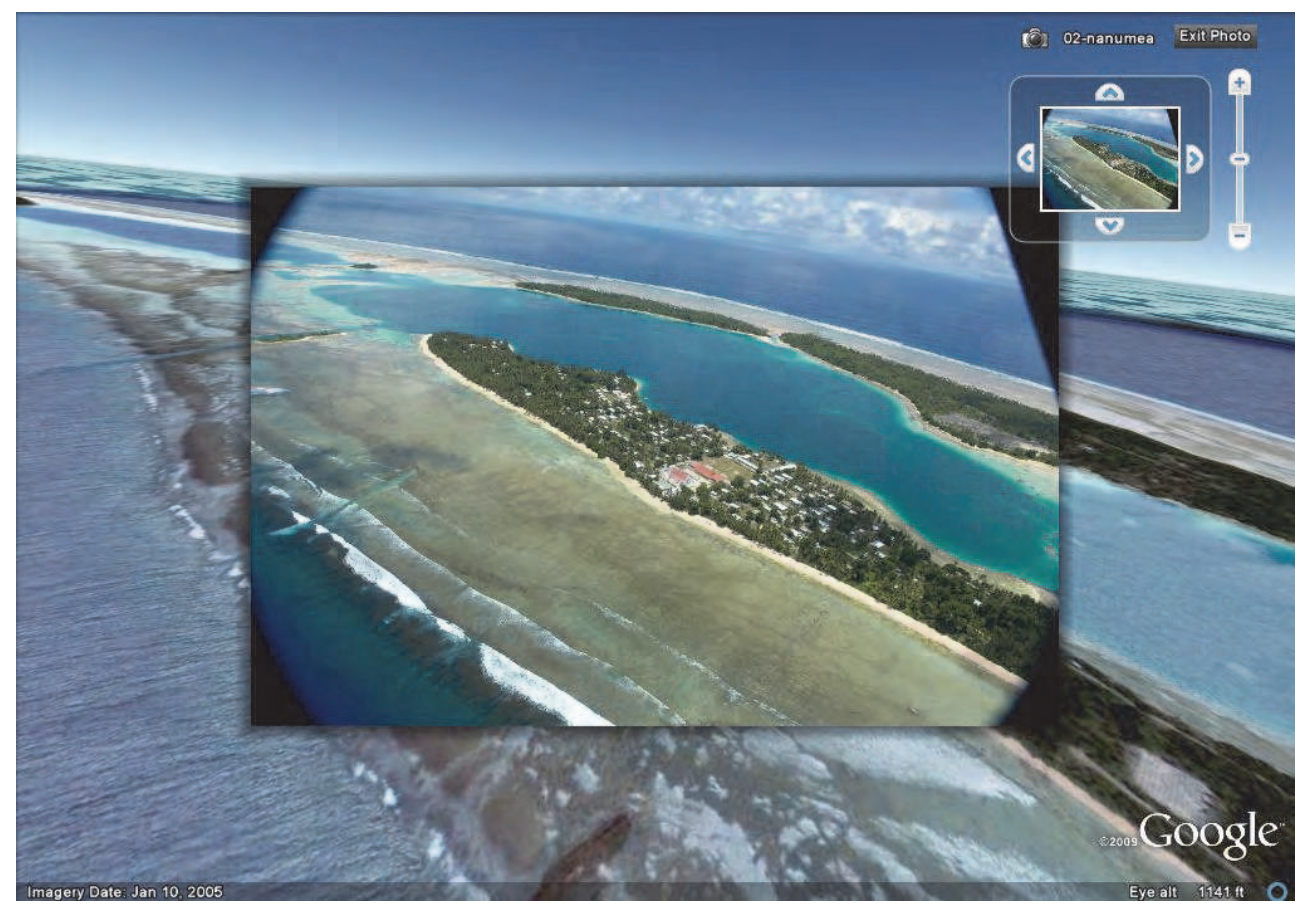

Fig. 7. UHD photo overlay 


\subsection{Overlay changing according to its altitude}

In order to naturally deepen the understanding of Tuvalu by the user carrying out the operation, it is designed so the detailed information on the nation of Tuvalu and this project will be displayed gradually (Fig. 8) as the user zoom-in to Tuvalu.

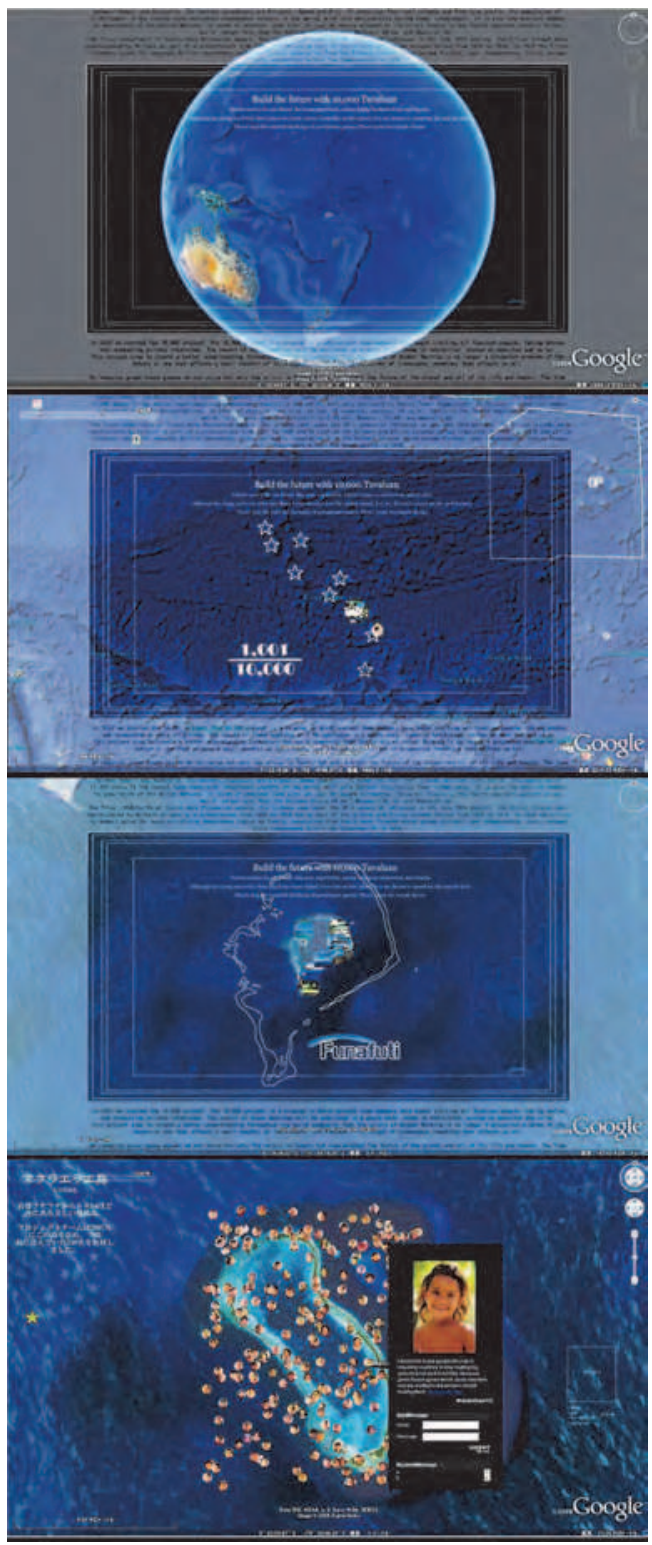

Fig. 8. Overlay changing according to its altitude 


\subsection{System structure}

The system structure of the "Tuvalu Visualization Project" is described below:

3.4 Portrait and interview record: it is stored in the database (MySQL) after being correlated to each other, and it is retrieved through the PHP script generating the kml dynamically. The location oriented display and random display mode is switchable by the use of the network link.

3.5 Sending the comment and visualization of communication: the comments to the database is stored by retrieving the PHP script of the server from the interface of Google Earth. When the comment record and the line display is updated, the newest data is loaded to the client side when the view is refleshed on Google Earth.

3.6 Landscape photographs (with GPS information): after granting the creative-commons license, they are uploaded to the photograph sharing service, and are retrieved from the static $\mathrm{kml}$ file.

3.6 Landscape photographs (for Ultra High Definision photograph overlay): after implementing the tile separation function, they are stored in the directory in the Web, and are retrieved from the static $\mathrm{kml}$ file.

3.7 Overlay: it is stored in the directory on the $\mathrm{Web}$, and is retrieved from the static $\mathrm{kml}$ file. All of these $\mathrm{kml}$ files are set to be read via the single network link $\mathrm{kml}$ file which the client will download. Still, the actual transmission uses the $\mathrm{kmz}$ file which is compression of $\mathrm{kml}$. Also, all of the $\mathrm{kml}$ file mentioned above is made public on the website. It is recommended to be consulted together with the $\mathrm{kml}$ reference.

\section{Considerations}

The "Tuvalu Visualization Project" was able to be experienced by many user audience through the internet, as well as at real exhibitions.

\subsection{Internet release and response}

Out of the contents of this art work, 3.6 mapping of landscape photographs was released on the internet on August 3rd, 2009, and 3.4 mapping of portraits and interview record and contents of 3.5 visualization of communication were both released on August 30th, 2009. The actual results of the access at the time of writing this thesis (March 25th, 2010) is as below.

Web site access: 13270 times (PV)

kmz file downloads: 5120 times

YouTube replays: 6377 times

Comments contributed: 158, from 6 countries

It is mentioned many times in places such as the internet news sites, blogs, and twitter. The comment, "I can understand very well where Tuvalu is, what kind of faces the people living there have, and what they feel towards the rise of the sea level" is unattainable by just having the photographs and the interview record on the Web page. It is speculated that this art work has achieved its purpose of telling the multifaceted realities of remote place via the digital globe. Many comments were made which display the common awareness of the issue in the global scale, as well as an intimacy with the people of Tuvalu,as the following show: "You are very courageous we support you and are spreading your message in the U.S. Thank you for the insight and for speaking up for social justice." "Dear Valoa-I passionately want the same thing. You did not create the problem-we did! Greetings to you 
and your family." It is conceivable that this fact exhibits the purpose of the art work, mentioned in 1.1, was achieved, which is to create a sense of solidarity through the visualization of the pseudo-synchronous communication - the feature of this work - through the webcasting via the digital globe.

\subsection{Real exhibitions and the response of the audience}

So far, this art work has been exhibited at conferences and festivals within and outside of the country, and had the opportunity to be experienced by a large number of audience. In many occasions, the audience viewed the screen from a distance at first. After having interest in the land of Tuvalu, portraits and landscape photographs expressed three-dimensionally on the digital globe, as well as the spread of communication visualized on the global scale, moved onto the actual operation, which involved inspecting the land of Tuvalu as well as the portraits and landscape photos, and contributing comments. Some examples of the feedbacks of the audience are as follow:

Those related to the land, such as "It is around here on Earth", "It is so far from Japan", "It is so close to sea level", "It is already sinking"

Those related to the photographs of the people of Tuvalu and their interview records, such as "The people's smiles are wonderful", "This person has such a dream", "I can see that they are normal people just like us"

Those related to the daily scenes, such as "It is interesting how the pigs are walking the public road", "It is unexpected to see many cars running", "It is a problem that a dumping ground for trash is created"

Those related to the communication function, such as "Comments from so many nations are contributed", "I want to write a comment, too"

These opinions were uttered sequentially as the audience followed the operation procedure. Looking at this, it is presumed that the communication of the reality of remote place using a digital globe - enabling inspection of the situation of the local area three-dimensionally, as well as the creation of solidarity through the visualization of pseudo-synchronous communication - appeal to the psychology of the audience, and achieve the purpose of this art work stated in chapter 1.1 .

\subsection{Problem areas and points of improvement}

At the first time of this exivision, the client software of the Google Earth needs to be downloaded and installed and this has become a hurdle to view the art work. But now, the users can use this contents on Internet Browser without download and install. Also, in the event of internet publication, it is inevitable that most likely a user familiar with the operation of Google Earth will experience the art work. However, in the exhibits at real venues, it is not always the case. For the audience not familiar with the operation of Google Earth, they may only view the art work from a distance, or even if they did operate it, some were zooming onto a point not related to the art work. Even though such audience were able to operate more smoothly after receiving instruction from a staff, it took more time to understand the purpose of the art work. It is conceivable that improvement such as implementing operation interface or auto-pilot function, other than the keyboard and mouse is needed in regards to this point. 


\section{Conclusion and outlook}

In this thesis, the net art work using the digital globe on the internet, the "Tuvalu Visualization Project" is presented, having the function of both the photography archive telling the realities of the people living in "Tuvalu" and their daily life, as well as the communication platform.

In conclusion, it is considerble that this fact exhibits the purpose of the study as stated in introduction.

The authors intend to keep creating opportunities to recognize anew the local problems globally, through a group of net art works starting with the above mentioned.

At the internet publication and real exhibits of this art work, there were opinions desiring projects with the same purpose in other parts of the world.

And also, it is presumed that this work can create a users' community through the visualization of pseudo-synchronous communication between remote place and users using a digital globe.

The curious instance, in the response to the internet as stated in 4.1,a user who moved to America from Tuvalu found an acquaintance residing in Tuvalu through the art work, and contributed a comment. This case went beyond the authors' supposition, and indicate the creation of a social network connecting the residents of Tuvalu and the audience with each other. But the users become enrolled in the archive only as senders of messages.

In the future, it is needed that to consider the way of work which not only owners of information can release the archive and collect comments, using the merit of Internet, but all users can provide their own information to archive and enjoy contributing their intelligence to community.

And the turning of the scape of the internet community is so fast, the analyses of access log and coordinating with the popular web contents and services at all times are necessary to continue inducing users to this work.

In the future, we plan to make improvements as stated above, as well as continue creating new archive work which is able to use in many fields.

\section{Acknowledgements}

The authors would like to show our deep appreciation to Photon Inc., DIGITAL CONTENTS EXPO/ASIAGRAPH2009, and each person involved in the Japan Media Art Festival held by the Agency for Cultural Affairs, for their utmost cooperation in creating this art work as well as in its exhibition.

\section{References}

INTERNET watch (2009). “The Protest Activity Against Iran on Twitter, etc., in Relations with the Democratization Strategy of the United States."In: Internet watch, 22.06.2009, Available from http:/ /internet.watch.impress.co.jp/docs/news/20090622 295583.html

Ikuo. Ohash. (2009) Towards Construction of the Global Information Society - Movement and Issues of the International Society Surrounding the Digital Divide. (Feature Article, ICT Industry as a Turning Point)). Creation of Intellectual Property, Knowledge cre-ation and integration, Public Relations Department, Nomura Research Institute, 17(3),pp.6-35 (2009.03) 
International Telecommunication Union. Internetindicators: Hosts, Users and Number of PCs http://www.itu.int/ITU-D/ict/statistics/

Kougaku. Takeda.(2006). The Realities of All Existing Things and the Ultimate Nature of All Things (tathata). All Existing Things as Realities", "Origin of Things"; Journal of Indian and Buddhist Studies, 55(1), pp.92-96 (2006.12)

Shoji. Sagawa.(1999): Joint Studies: Realities of Damage by the Atomic Bomb on Hiroshima and Nagasaki, Shin-Nihon Publishing Company (1999.07)

Mao. Ishikawa.(1995). Okinawa and Self-Defense Force Captured by a Female Photographer, Koubunken (1995.05)

Nobuko. Oyabu. Stand - Choosing to Stand Up, Word of Press Ministries (2007.10)

STALLABRASS Julian: Internet art: the onlineclash of culture and commerce; Tate Publishing,United Kingdom (2003.04)

Niwango Inc.: "Nico Nico Douga"; Winner of Honorary Mention of Digital Communities category, Prix ARSElectronica 2008(2008.09)

Colin Ellard: YOU ARE HERE Why We Can Find Our Way to the Moon, but Get Lost in the Mall; Doubleday Publishing, United Kingdom(2009.07)

Sensorium: "Sensorium"; Golden Nica of .net cat-egory, Prix ARS Electronica 1987(1987.09).

NTT Intercommunication Center: ICCONLINE "Art Meets Media: Adventure of the Perceptions"

http://www.ntticc.or.jp/Archive/2005/art meets media/ Mediaonline/netartj.html

Masaki Fujihata: "Field-Works" http:/ / www.?eld-works.net/

Life Slice Laboratory: "Life Slice Calendar and Life Slice World Map"; Exhibition of the 6th Japan Media Arts Festival Award-Winning Works (2003.02)

Masashige Motoe, Yasuto Nakanishi, Shohei Matsukawa: JIKUKAN-POEMER: Experimentation of Web Geographic Information System Using a Mobile Phone equipped with a Camera and a GPS at Tama Center and its Evaluation; Architectural Institute of Japan Academic Lecture Series (A-2, Fire Proof, Oceanography, Information System Technology ) 2004,pp.531-532 (2004.07)

Photon: Sakura Mapping http:/ / mapping.jp/

International Crisis Group: Crisis in Darfur http://www.crisisgroup.org/en/key-issues/preventing-implosion-in-sudan.aspx

Henri Cartier-Bresson: "Henri Cartier-Bresson(Masters of Photography Series)"; Aperture,France (1997.09)

NPO Tuvalu Overview: “Build the Future with10000 Tuvaluans” http://10000.tv/

MaxMind,Inc.: MaxMind - GeoIP-IP Address Lo-cation Technology http://www.maxmind.com/app/ip-location

Hidenori Watanave Laboratory: “Tuvalu Visual-ization Project" http://tv.mapping.jp/

Google,Inc.: KML Reference - KML - Google Code http://code.google.com/intl/ ja/apis/kml/documentation/kmlreference.html

Mainichi Newspaper: Mainichi.jp"Living in Tuvalu: Recreating the Island Nation with a 3D Contents" http:/ / mainichi.jp/life/ecology/graph/20090806/

GIGAZINE: “'Tuvalu Visualization Project' Mapping the Voices of the People Living in Tuvaluon Google Earth"

http://gigazine.net/index.PHP?/news/comments/20100204jmaf2009tuvaluvisuali zation project/

Hidenori Watanave, Makiko Suzuki, YuichiWatanabe and Shuichi Endo: "Tuvalu Visuaiization Project " ASIAGRAPH 2009 in Tokyo;Artech (Art Works And Technolo-Gies Exhibits), Miraikan, Japan (2009.10) 
Shuichi Endo and Hidenori Watanave, "Tuvalu Visualization Project " Exhibition in Tu,svalu Overview ' exhibit space at United NationsClimate Change Conference 2009 in Copenhagen(COP15), Copenhagen, Denmark (2009.11)

Hidenori Watanave/ Shuichi Endo: "Tuvalu Visualization Project;" Exhibition of the 13th Japan Media Arts Festival Award Winning Works, The National Art Center (2010.02)

Hidenori Watanave, Makiko Suzuki Harada andShuichi Endo: "Tuvalu Visualization Project (4KUHD Version) " 12th International Conference on;Virtual Reality - Laval Virtual, Laval Virtual Rev-olution 2010, Theatre de Herce - Salle Polyvalente(Multifunction Hall), Laval, France ( 2010.04) 


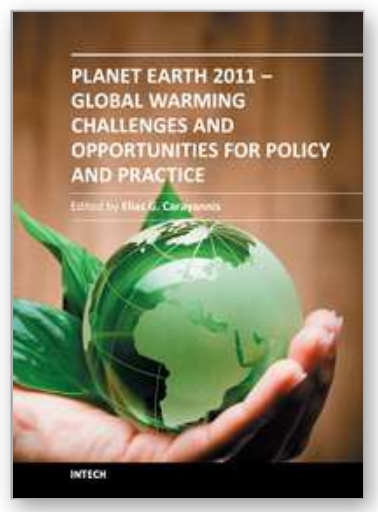

\section{Planet Earth 2011 - Global Warming Challenges and Opportunities for Policy and Practice}

Edited by Prof. Elias Carayannis

ISBN 978-953-307-733-8

Hard cover, 646 pages

Publisher InTech

Published online 30, September, 2011

Published in print edition September, 2011

The failure of the UN climate change summit in Copenhagen in December 2009 to effectively reach a global agreement on emission reduction targets, led many within the developing world to view this as a reversal of the Kyoto Protocol and an attempt by the developed nations to shirk out of their responsibility for climate change. The issue of global warming has been at the top of the political agenda for a number of years and has become even more pressing with the rapid industrialization taking place in China and India. This book looks at the effects of climate change throughout different regions of the world and discusses to what extent cleantech and environmental initiatives such as the destruction of fluorinated greenhouse gases, biofuels, and the role of plant breeding and biotechnology. The book concludes with an insight into the socio-religious impact that global warming has, citing Christianity and Islam.

\section{How to reference}

In order to correctly reference this scholarly work, feel free to copy and paste the following:

Makiko Suzuki Harada, Hidenori Watanave and Shuuichi Endou (2011). Tuvalu Visualization Project - Net Art on Digital Globe: Telling the Realities of Remote Places, Planet Earth 2011 - Global Warming Challenges and Opportunities for Policy and Practice, Prof. Elias Carayannis (Ed.), ISBN: 978-953-307-733-8, InTech, Available from: http://www.intechopen.com/books/planet-earth-2011-global-warming-challenges-andopportunities-for-policy-and-practice/tuvalu-visualization-project-net-art-on-digital-globe-telling-the-realities-ofremote-places

\section{INTECH}

open science | open minds

\section{InTech Europe}

University Campus STeP Ri

Slavka Krautzeka 83/A

51000 Rijeka, Croatia

Phone: +385 (51) 770447

Fax: +385 (51) 686166

www.intechopen.com

\section{InTech China}

Unit 405, Office Block, Hotel Equatorial Shanghai

No.65, Yan An Road (West), Shanghai, 200040, China

中国上海市延安西路65号上海国际贵都大饭店办公楼 405 单元

Phone: +86-21-62489820

Fax: $+86-21-62489821$ 
(C) 2011 The Author(s). Licensee IntechOpen. This chapter is distributed under the terms of the Creative Commons Attribution-NonCommercialShareAlike-3.0 License, which permits use, distribution and reproduction for non-commercial purposes, provided the original is properly cited and derivative works building on this content are distributed under the same license. 